\title{
Development of a BMI-Assigned Stunkard Scale for the Evaluation of Body Image Perception Based on Data of the SOS Reference Study
}

\author{
Verena Parzer ${ }^{a}$ Kajsa Sjöholm ${ }^{b}$ Johanna Maria Brix ${ }^{a, c}$ Per-Arne Svensson b, d \\ Bernhard Ludvik ${ }^{a}$ c Magdalena Taube ${ }^{b}$ \\ aDepartment of Medicine I, Clinic Landstrasse Vienna, Vienna, Austria; ${ }^{b}$ Institute of Medicine, Department of \\ Molecular and Clinical Medicine, Sahlgrenska Academy at University of Gothenburg, Gothenburg, Sweden; 'Karl

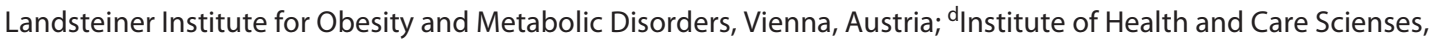 \\ Sahlgrenska Academy at University of Gothenburg, Gothenburg, Sweden
}

\section{Keywords}

Body image perception - Figure rating scale $\cdot$ Stunkard Scale

\begin{abstract}
Introduction: Stunkard's figure rating scale is a widely used tool to assess weight status and, more recently, body image perception in people with obesity. However, large population-based studies on Europeans linking this scale's silhouettes with measured BMI values are lacking. Therefore, we used measured weight and height data from the Swedish Obese Subjects (SOS) reference cohort to assign a mean BMI to each of the 9 Stunkard Scale silhouettes and to define silhouette cutoff values for categorizing people with obesity and overweight. Methods: A total of 1,128 participants from the SOS reference cohort were included $(54 \%$ females, $\mathrm{BMI}=25.2$ [ranging from 17.6 to 45.4$] \pm 3.8 \mathrm{~kg} / \mathrm{m}^{2}$, and age $=$ 50 [ranging from 36 to 62 ] \pm 7 years [means \pm standard deviation]). Patients estimated their own body size by choosing a silhouette of the Stunkard Scale. A mean BMI, based on measured weight and height, was assigned to each male and female silhouette of the Stunkard Scale. Measured BMI values were compared with BMI values calculated by simple linear regression analysis. ROC analysis was used to test accu-
\end{abstract}

karger@karger.com www.karger.com/ofa

Karger $\stackrel{\text { ' }}{5}$

GOPEN ACCESS
(C) 2021 The Author(s)

Published by S. Karger AG, Basel

This is an Open Access article licensed under the Creative Commons Attribution-NonCommercial-4.0 International License (CC BY-NC) (http://www.karger.com/Services/OpenAccessLicense), applicable to the online version of the article only. Usage and distribution for commercial purposes requires written permission. racy of discrimination and the Youden index to assess optimal cutoff. Results: Figure ratings and BMI were strongly correlated in men, $r(518)=0.76, p<0.001$ and women, $r$ $(606)=0.80, p<0.001$. Silhouette selection significantly predicted $B M I$ values in men, $\beta=16.03, t(518)=25.30, p<0.001$, and women, $\beta=12.06, t(606)=32.98, p<0.001$, and explained a significant proportion of variance in BMl values in men, $R^{2}=0.55, F(1,518)=639.98, p<0.001$, and women, $R^{2}=0.64, F(1,606)=1,087.88, p<0.001$. ROC curve analyses resulted in an optimal cutoff value of 6 for identifying people with obesity and 5 for overweight. Conclusion: Stunkard's figure rating scale can be used with confidence to assess weight status. Silhouette selection accurately classifies subjects as overweight or obese. (c) 2021 The Author(s)

Published by S. Karger AG, Basel

\section{Introduction}

Globally, obesity is a growing health problem with increasing prevalence rates [1]. A frequently used tool to assess an individual's weight status is BMI [2]. Unfortu-

B.L. and M.T. shared last authors.

Correspondence to:

Magdalena Taube, magdalena.taube@gu.se 
nately, BMI does not consider body fat distribution, which substantially influences metabolic health and mortality rates [2]. More information about body fat distribution can be obtained by additional measurements, for instance waist circumference, which is a good predictor of abdominal visceral obesity [3]. Recently, figure rating scales have gained popularity as an additional source of information or as a substitute in settings where anthropometric data cannot be obtained [4-6]. The first standardized and validated figure rating scale was introduced by Stunkard et al. [7] and was initially developed to assess the weight status of adoptees' parents in the Danish Adoption Register. The scale consists of 9 male and 9 female body figures that increase gradually in size from very thin to very obese [7]. Previous studies have shown that figure rating scales can be validly used to estimate anthropometric characteristics and to categorize people with overweight and obesity $[4,8,9]$. Those studies were conducted in large study populations but limited by the use of self-reported weight and height [4], a nonstandardized figure rating scale [8] or limiting the validity in a Caucasian sample as the study population was of Mexican origin [9].

Lately, the Stunkard Scale has been increasingly implemented to evaluate body image perception and body dissatisfaction in different populations [10-12]. To assess body image perception, participants are asked to indicate the silhouette of the Stunkard scale, which mostly resembles their current body figure. Indicated silhouettes and corresponding BMI values can then be compared between different groups [10]. Indicated silhouettes may also be classified into weight categories from underweight to obese and can then be compared with current BMI [13]. Body dissatisfaction can be estimated by the discrepancy between the indicated current and ideal body figure $[11,13]$. In the CARDIA study, Stunkard Scale was used to assess the influence of body image perception and satisfaction on weight change over the years. An underestimation of body size and a higher degree of body satisfaction in obese women were associated with weight gain over the years [13].

To our knowledge, there is no large population-based study linking Stunkard's figure rating scale with BMI values from measured weight and height in a European population. To establish a BMI-assigned Stunkard Scale, we used data from the Swedish Obese Subjects (SOS) reference study to assign a particular BMI based on measured weight and height to each silhouette of the Stunkard Scale.

\section{Materials and Methods}

\section{Study Population and Study Design}

Data from the SOS reference study, a substudy of the SOS study, which was the first prospective, controlled outcome trial investigating the long-term effects of bariatric surgery, were used. The SOS reference study is a cross-sectional study and was designed to serve as a reference cohort to the SOS intervention trial in subjects with obesity. The study protocol was approved by the following Ethics Committee: Medicinska fakultetens Forskningsetiska kommitté, Götenborg (reference number 124-94). Written informed consent was obtained from all participants. The study was conducted ethically in accordance with the World Medical Association Declaration of Helsiniki. Between August 1994 and December 1999, 1,135 randomly selected individuals between the age of 37 and 61 years living in the cities of Mölndal and Örebro, Sweden, were recruited $[14,15]$. Participants were asked to indicate their own body figure by choosing a silhouette of the Stunkard Scale [7]. At the same time, weight and height were measured, and BMI was calculated.

\section{Statistics}

The data were analyzed by sex using descriptive statistics. Mean, standard deviations, and 95\% confidence intervals (CIs) were used to describe the general characteristics of the sample. Normal distribution was tested by the Kolmogorov-Smirnov test.

The mean BMI of all study participants choosing the same silhouette to describe their own body figure was calculated and assigned to the corresponding silhouette of the Stunkard Scale. No participant chose male silhouette number 9 , and therefore, this missing value was calculated by extrapolation. Spearman correlations between figure ratings and $\mathrm{BMI}$ were calculated. A simple linear regression analysis was performed separately for men and women and used to test the association between the independent variable of silhouette selection and the dependent variable of measured BMI. Subsequently, the regression equation was used to calculate BMI values for each male and female silhouette of the Stunkard Scale.

Furthermore, we used receiver operating characteristic (ROC) curves to test whether the silhouettes can be used to classify a person as obese $\left(B M I \geq 30 \mathrm{~kg} / \mathrm{m}^{2}\right)$ or overweight $\left(\mathrm{BMI} \geq 25 \mathrm{~kg} / \mathrm{m}^{2}\right)$. The area under the ROC curve (AUC) was used as a measure of accuracy. The most appropriate body figure with regard to sensitivity and specificity was identified as a cutoff for classifying an individual as obese or overweight using the Youden index [16]. Analyses were performed using statistical package IBM SPSS Statistics 21 .

\section{Results}

A total of 1,128 study participants were included, of which $0.4 \%(n=5)$ were underweight, $52 \%(n=590)$ normal weight, $37 \%(n=425)$ overweight, and $10 \%(n=115)$ obese (Table 1). BMI values and silhouette ratings from 520 male and 608 female participants were available and included for the calculations. A mean BMI was assigned to each male and female silhouette of the Stunkard Scale (Fig. 1). 
Table 1. General characteristics of the study population

\begin{tabular}{|c|c|c|c|c|}
\hline Variable & Mean & Min & Max & IQR \\
\hline \multicolumn{5}{|l|}{ Total, $n=1,128$} \\
\hline Age, years & $50 \pm 7$ & 36 & 62 & - \\
\hline BMI & $25.2 \pm 3.8$ & 17.6 & 45.4 & 4.83 \\
\hline \multicolumn{5}{|l|}{ Males, $n=520$} \\
\hline Age, years & $49.8 \pm 7.0$ & 36.0 & 61.8 & - \\
\hline BMI & $25.8 \pm 3.4$ & 17.9 & 42.2 & 4.38 \\
\hline Silhouettes & - & 1 & 8 & 2 \\
\hline \multicolumn{5}{|l|}{ Females, $n=608$} \\
\hline Age, years & $49.3 \pm 7.0$ & 35.7 & 61.6 & - \\
\hline BMI, $\mathrm{kg} / \mathrm{m}^{2}$ & $24.7 \pm 4.1$ & 17.6 & 45.4 & 4.77 \\
\hline Silhouettes & - & 1 & 9 & 1 \\
\hline
\end{tabular}

IQR, interquartile range.

For example, figure number 1 corresponds to a mean BMI of $19.14 \mathrm{~kg} / \mathrm{m}^{2}$ in men and $17.88 \mathrm{~kg} / \mathrm{m}^{2}$ in women. Male body figure numbers 1-4 can be classified as normal weight, numbers 5 and 6 as overweight, and numbers 7-9 as obese. Female body figure number 1 can be classified as underweight, numbers $2-4$ as normal weight, numbers 5 and 6 as overweight, and numbers 7-9 as obese. Figure ratings and BMI were strongly correlated in men, $r(518)=0.76, p<$ 0.001 , and women, $r(606)=0.80, p<0.001$.

Simple linear regression equations for predicting BMI based on silhouette selection were calculated for men and women. Silhouette selection significantly predicted BMI values in men, $\beta=16.03, t(518)=25.30, p<0.001$, and women, $\beta=12.06, t(606)=32.98, p<0.001$.

The regression equations are as follows ( $y$ is the BMI value and $x$ is the silhouette number from 1 to 9 ):

for men: $y=16.031+2.038 x$

for women: $y=12.062+2.810 x$

Silhouettes also explained a significant proportion of variance in BMI values in men, $R^{2}=0.55, F(1,518)=$ $639.98, p<0.001$, and women, $R^{2}=0.64, F(1,606)=$ $1,087.88, p<0.001$. The selection of a silhouette to describe the own body figure statistically explained $55 \%$ of BMI variance in men and $64 \%$ in women. Beta values indicate a $2.038 \mathrm{BMI}$ unit increase per silhouette change in men $(95 \% \mathrm{CI}=1.880 ; 2.196)$ and a 2.810 unit increase in women $(95 \% \mathrm{CI}=2.643 ; 2.978)$. Using regression equations, BMI values and their 95\% CIs were calculated for each male and female figure of the Stunkard Scale. Results are presented in Table 2.

A BMI-Assigned Figure Rating Scale

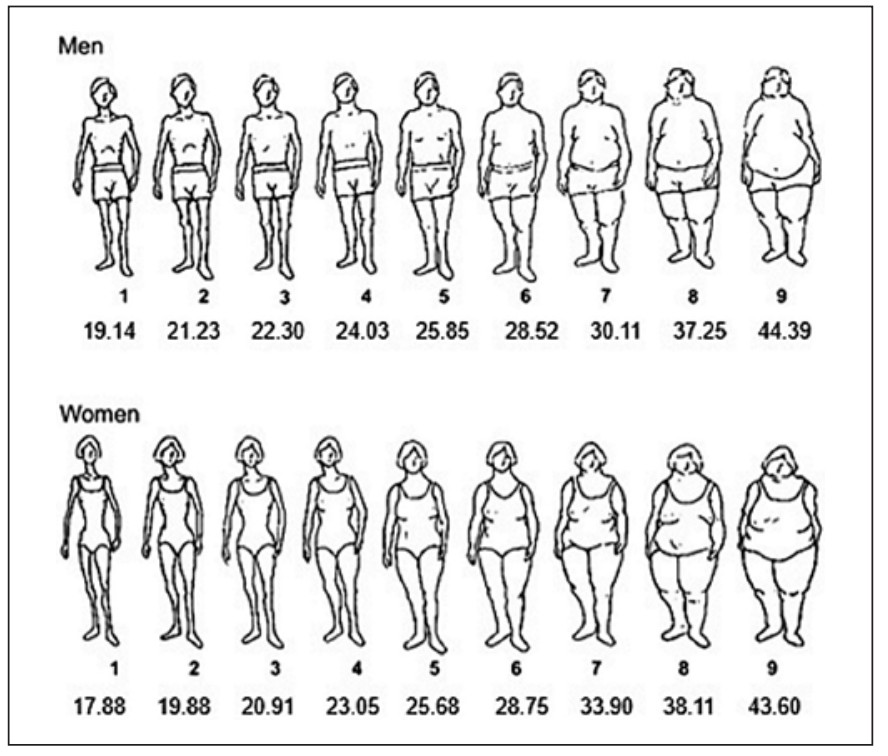

Fig. 1. BMI-assigned Stunkard Scale [7] based on data from SOS reference study. SOS, Swedish Obese Subjects.

ROC analyses were performed to test the ability of the silhouettes to correctly classify men or women as overweight $(\mathrm{AUC}=0.706[95 \% \mathrm{CI}=0.661 ; 0.751], p<0.001$ in men and $\mathrm{AUC}=0.762$ [95\% CI $=0.723 ; 0.801], p<$ 0.001 in women) or obese (AUC $=0.885[95 \% \mathrm{CI}=0.848$; $0.921], p<0.001$ in men and AUC $=0.919$ [95\% CI $=$ $0.891 ; 0.948], p<0.001$ in women) (Fig. 2). We estimated optimal silhouette cutoffs using the Youden method. For classifying obesity, sensitivity and specificity were optimal using silhouette number 6 as the cutoff value in both men and women and for classifying overweight silhouette number 5. Results of the ROC curve and Youden analyses are shown in Table 3.

\section{Discussion}

For the first time, we introduce a BMI-assigned Stunkard Scale based on measured weight and height data from a European-Caucasian population, which will allow the estimation of weight status and facilitate future research in the field of body image perception. Our results show that measured BMI values correlate well with chosen silhouettes. By simple linear regression analyses, we were able to confirm that BMI can be accurately estimated by silhouette selection. Furthermore, ROC analysis showed that figure ratings can classify individuals with obesity and overweight with high accuracy. 
Table 2. Mean measured BMI and mean BMI calculated by simple linear regression analysis and their 95\% CIs

\begin{tabular}{|c|c|c|c|c|}
\hline Silhouette number & $N$ & $\%$ & Mean BMI, 95\% CI & $\begin{array}{l}\text { Mean BMI by lin. regression, } \\
95 \% \text { CI }\end{array}$ \\
\hline \multicolumn{5}{|l|}{$\operatorname{Men}(n=520)$} \\
\hline 1 & 3 & 0.6 & $19.14(16.84 ; 21.44)$ & 18.07 (17.91; 18.23) \\
\hline 2 & 21 & 4.0 & $21.23(20.18 ; 22.28)$ & $20.11(19.79 ; 20.42)$ \\
\hline 3 & 51 & 9.8 & $22.30(21.91 ; 22.70)$ & $22.15(21.67 ; 22.62)$ \\
\hline 4 & 112 & 21.5 & $24.03(23.71 ; 24.34)$ & $24.18(23.55 ; 24.82)$ \\
\hline 5 & 174 & 33.5 & $25.85(25.57 ; 26.13)$ & $26.22(25.43 ; 27.01)$ \\
\hline 6 & 128 & 24.6 & $28.52(27.99 ; 29.04)$ & $28.26(27.31 ; 29.21)$ \\
\hline 7 & 27 & 5.2 & $30.11(29.05 ; 31.17)$ & $30.30(29.19 ; 31.40)$ \\
\hline 8 & 4 & 0.8 & $37.25(29.22 ; 45.28)$ & $32.34(31.07 ; 33.60)$ \\
\hline 9 & 0 & 0 & $44.39^{*}$ & $34.37(32.95 ; 35.80)$ \\
\hline \multicolumn{5}{|l|}{ Women $(n=608)$} \\
\hline 1 & 1 & 0.2 & 17.88 & $14.87(14.71 ; 15.04)$ \\
\hline 2 & 20 & 3.3 & $19.88(19.39 ; 20.36)$ & $17.68(17.35 ; 18.02)$ \\
\hline 3 & 77 & 12.7 & $20.91(20.59 ; 21.23)$ & $20.49(19.99 ; 21.00)$ \\
\hline 4 & 228 & 37.5 & $23.05(22.80 ; 23.30)$ & $23.30(22.63 ; 23.97)$ \\
\hline 5 & 171 & 28.1 & $25.68(25.31 ; 26.05)$ & $26.11(25.28 ; 26.95)$ \\
\hline 6 & 84 & 13.8 & $28.75(28.12 ; 29.39)$ & $28.92(27.92 ; 29.93)$ \\
\hline 7 & 22 & 3.6 & $33.90(32.07 ; 35.73)$ & $31.73(30.56 ; 32.91)$ \\
\hline 8 & 4 & 0.7 & $38.11(29.85 ; 46.37)$ & $34.54(33.21 ; 35.89)$ \\
\hline 9 & 1 & 0.2 & 43.60 & $37.35(35.85 ; 38.86)$ \\
\hline
\end{tabular}

CI, confidence interval. ${ }^{*}$ Calculated by linear extrapolation: $y^{9}=x^{7}+\left[\left(x^{8}-x^{7}\right) /\left(y^{8}-y^{7}\right)\right] \times\left(y^{9}-y^{7}\right)$.

The strong correlation between BMI and figure ratings in our study confirms results from a study in $>28,000$ participants using polyserial correlations between Stunkard's figure ratings and the log of self-reported BMI [4]. Similarly, this was also shown in a study population of Mexican adults with BMI values obtained from measured weight and height [9]. Figure ratings were also suggested as a useful tool to retrospectively differentiate obesity in the past [6].

As BMI corresponds well with figure ratings, we assigned a mean BMI to each silhouette to introduce a BMIassigned Stunkard Scale. Generally, the mean sample BMI values matched quite well with the values obtained by simple linear regression analyses for most silhouette numbers. For example, men who selected silhouette number 3 as representative of their own body figure had a mean BMI of $22.30 \mathrm{~kg} / \mathrm{m}^{2}$ compared with $22.15 \mathrm{~kg} / \mathrm{m}^{2}$ based on the regression model. A slight divergence of measured and calculated BMI values as well as the larger CIs were seen for silhouettes of lower and higher numbers, which might be due to smaller sample sizes for these silhouettes. This was also observed in previous studies [4, 9]. Compared to other studies, assigned mean BMI values for women and men are quite similar for the middle- ranged silhouettes [4]. They differ, however, for silhouette number 9 at the upper end of the figure rating scale with assigned BMI values ranging from above $40 \mathrm{~kg} / \mathrm{m}^{2}$ for both male and female silhouettes [4] to a BMI of 36.5 $\mathrm{kg} / \mathrm{m}^{2}$ for male silhouette number 9 [5]. Assigned BMI for silhouette number 9 differs by almost 7 BMI units between men and women in the latter study [5].

To our knowledge, this is the first BMI-assigned figure rating scale based on the original Stunkard Scale and measured BMI data in a large European-Caucasian population. Previous BMI assignments were based on data from self-reported weight and height $[4,5]$, another type of figure rating scale $[6,8]$, or a non-European study sample $[4,9]$. This scale can be considered as a standard for future studies in the field of body image perception in other European-Caucasian populations. Body image perception is an individual's estimation of their own body figure [17]. Body image distortion is defined as "the failure to evaluate the size of one's body accurately" [18] and is a recognized key symptom of anorexia nervosa and therefore well-studied [19]. Lately, more attention has been paid to body image distortion as a possible feature of obesity. It might play a role in the regulation of weight status as obese patients displayed a higher degree of dis- 


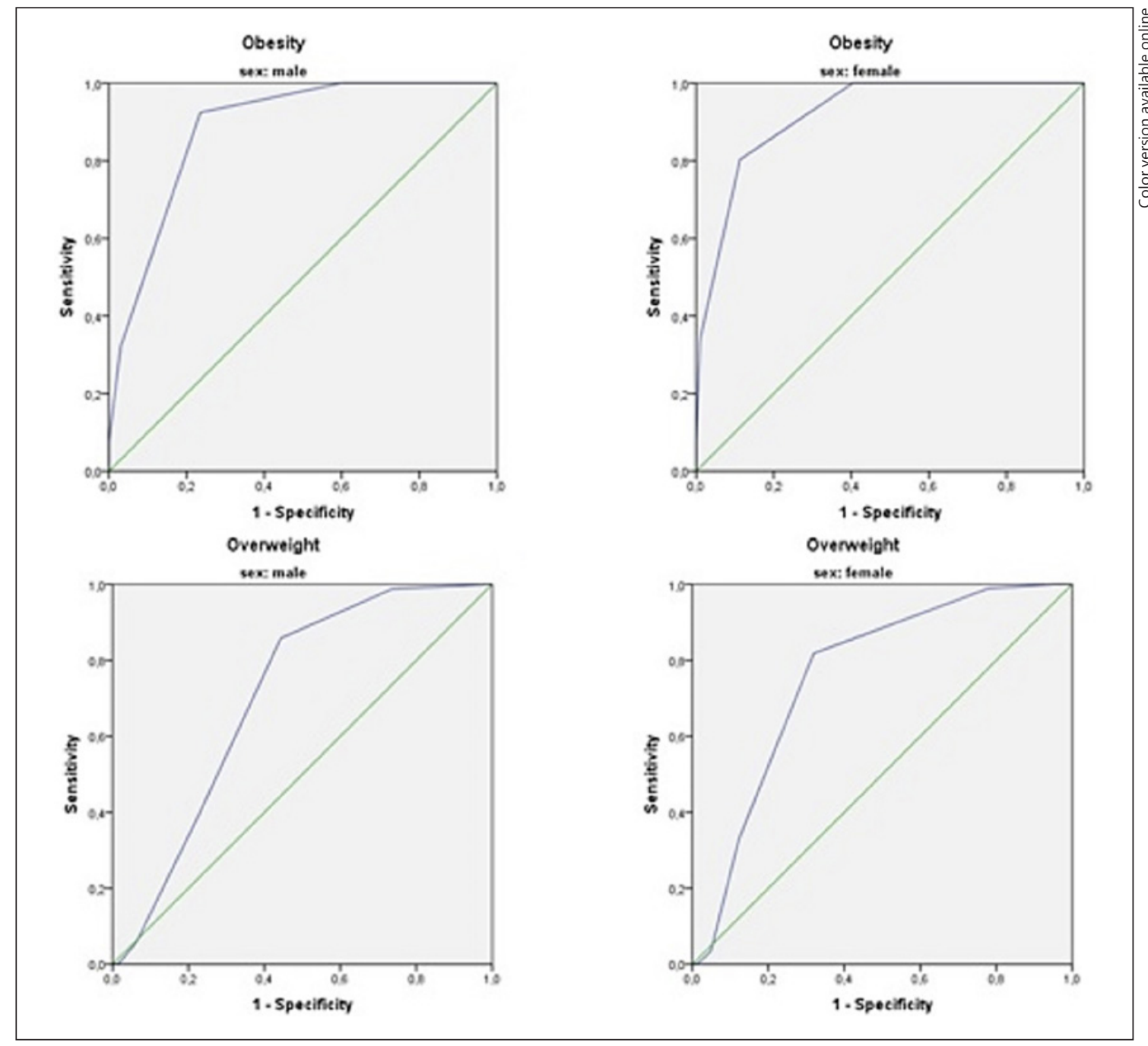

Fig. 2. ROC curves for classifying people with obesity and overweight in men and women. ROC, receiver operating characteristic.

Table 3. Results of ROC curve analyses and Youden cutoff values for identifying obesity and overweight in consideration of sex

\begin{tabular}{lllll}
\hline Obesity & AUC & $\begin{array}{l}\text { Sensitivity/ } \\
\text { specificity }\end{array}$ & $\begin{array}{l}\text { Silhouette cutoff value } \\
\text { for obesity }\end{array}$ & $\begin{array}{l}\text { Youden } \\
\text { index }\end{array}$ \\
\hline $\begin{array}{llll}\text { Men } \\
\text { Women }\end{array}$ & $0.885(95 \%$ CI $0.848 ; 0.921)$ & $\begin{array}{l}0.92 / 0.76 \\
0.80 / 0.89\end{array}$ & $\begin{array}{l}\geq 6 \\
0.68\end{array}$ \\
\hline Overweight & AUC & Sensitivity/ & $\begin{array}{l}\text { Silhouette cutoff value } \\
\text { for overweight }\end{array}$ & $\begin{array}{l}\text { Youden } \\
\text { index }\end{array}$ \\
\hline Men & & specificity & $\geq 5$ & 0.69 \\
Women & $0.706(95 \%$ CI $0.661 ; 0.751)$ & $0.88 / 0.69$ & $\geq 5$ & 0.65 \\
\hline
\end{tabular}

AUC, area under the curve; ROC, receiver operating characteristic. Youden Index is defined as sensitivity plus specificity minus $1[16]$. 
tortion [20], and body size underestimation was associated with weight gain in patients with obesity [13]. To evaluate body image perception, the body perception in$\operatorname{dex}(\mathrm{BPI})$, which is defined as the individual's estimated size divided by the actual size, can be applied [21]. A BPI above 1 indicates an overestimation of the own body size, and a BPI below 1 indicates an underestimation. To calculate the BPI, a BMI-assigned Stunkard Scale is needed to replace the individual's perceived body figure on the Stunkard Scale with a corresponding BMI.

In our study, we tested the Stunkard Scale as a means to assess weight status. In simple linear regression models, $55 \%$ of BMI variance in men and $64 \%$ in women were explained statistically by silhouette selection. Other studies also reported BMI variances above $50 \%[8,9]$, confirming that figure rating scales can be used as a diagnostic tool to assess weight status. Our cutoff values for identifying subjects with overweight and obesity were 5 and 6 , respectively, for both men and women. Accuracy for detecting overweight and obesity was high with greater AUC values in women than men. A cutoff value of 6 for identifying subjects with obesity was also reported in previous studies $[4,9]$.

Some limitations of the current study need to be considered. The mean BMI of male silhouette number 9 was calculated by extrapolation. As already mentioned before, few study participants with extremely low and high weight were included. This might explain why measured and calculated BMI values diverge and CIs become larger for silhouettes of lower and higher numbers, which was also observed in the previous studies [4, 9]. Therefore, assigned BMI values of silhouette numbers 1 and 9 should be used with caution. More data from individuals with extreme weights are needed, although interpretation might be difficult as distorted body image perception seems to be particularly present in people with extremely low or high weight. In that regard, patients with anorexia nervosa were found to overestimate their body size [22], while patients with obesity were found to underestimate their body size [13]. Information on the other silhouettes can be used with more confidence as the sample size is larger, and the CIs derived from regression analyses are quite narrow.

Furthermore, it would have been desirable to assign mean BMI values to each silhouette in 1 study sample and test the regression and ROC analyses in another. However, we do not have access to another sample of Caucasians of acceptable size. Splitting our sample, thereby reducing the sample size, would have resulted in a too limited number of people with extremely low and high BMI, thereby reducing the validity of assigned mean BMI values for the silhouettes with low and high numbers.

In this study population, mean age was 50 years, ranging from 36 to 62 years, possibly limiting generalizability of our results. Although data were collected before 2000, it can be assumed that they are still valid. While body ideals might have changed over the past due to the presentation of thin and muscular bodies as most desirable [23], there is no proof in the literature that body image perception has changed over the last years.

There are also some issues with figure rating scales in general. First of all, the number of presented figures is limited and information may get lost as, in reality, body size is a continuous variable [24]. Figure rating scales can be used as proxies for anthropometric data, but for assessing body composition in a more precise manner, other methods such as body impedance analyses are needed [25].

However, other methods to evaluate body image are time-consuming and therefore not easily feasible in large patient populations or clinical practice [20,26-28]. The method of presentation of figure rating scales can also be questioned. The presentation of each silhouette on a separate piece of paper and in random order is recommended by some authors to minimize potential bias, particularly when participants have to answer multiple questions [24]. However, all these recommendations would restrict the advantages of figure rating scales as easily and quickly applicable tools. Some authors also criticize that Stunkard's silhouettes may not be large enough regarding populations with high obesity prevalence rates [9]. Furthermore, our data might not be applicable to other populations than European Caucasians due to different characteristics. For example, body ideals, body dissatisfaction, and body image disturbances differ among different cultures [29].

Our study's strengths include a large sample size of 1,128 participants. Calculations are based on measured, instead of self-reported, BMI. This is of high relevance as analyses based on the National Health and Nutrition Examination Survey (NHANES) with a sample of 8,208 men and 8,606 women showed that both men and women significantly overestimated their height. While men tended to overestimate, women tended to underestimate their weight, and BMI was underestimated to a greater extent in women [30].

In conclusion, we are the first to demonstrate a BMIassigned Stunkard Scale based on measured weight and height data in a large European-Caucasian sample. Moreover, we tested this new scale by simple linear regression 
analyses and ROC curves and propose its use as a proxy to identify individuals with obesity and overweight. This scale may be helpful in the evaluation of body image perception in research settings and data collection in clinical practice by providing an easy and fast way to estimate weight status, when measurement of weight and height is not feasible.

\section{Statement of Ethics}

Approval of the relevant ethical committee was received before the study was started - Medicinska fakultetens Forskningsetiska kommitté, Götenborg (reference number 124-94). All the procedures performed were in accordance with the standards of the ethical committee and with the 1964 Helsinki declaration [31]. Written informed consent was obtained from all individual participants included in the study.

\section{Conflict of Interest Statement}

V. Parzer, P.-A. Svensson, and K. Sjöholm have no conflicts of interest to declare. J. M. Brix received honoraria from Astra Zeneca, Boehringer Ingelheim, Eli Lilly, MSD, Novo Nordisk, and Sanofi aventis. B. Ludvik received grant support and honoraria for research projects and advice from Eli Lilly, Novo Nordisk, Sanofi, Boehringer Ingelheim, Astra Zeneca, Bayer, and Amgen. B. Ludvik is an associate editor in the journal Obesity Facts. Magdalena Taube holds stocks in Umecrine $\mathrm{AB}$ and has a patent licensed to Umecrine AB.

\section{Funding Sources}

The study obtained funding from the Swedish Research Council (2020-01303), the Swedish state under the agreement between the Swedish government and the country councils, the ALF agreement (ALFGBG-717891), and the Swedish Diabetes foundation (2019-417).

\section{Author Contributions}

V. Parzer performed statistical analysis and wrote the manuscript with input from all the authors. K. Sjöholm aided in interpreting statistical results and revised the manuscript. J. M. Brix helped in performing statistical analysis. P.-A. Svensson helped in interpreting statistical results and revised the manuscript. B. Ludvik conceived main parts of the project. $M$. Taube supervised the project and contributed to main ideas of the project. All the authors approved the final version of the manuscript.

\section{References}

1 Collaboration NRF. Trends in adult bodymass index in 200 countries from 1975 to 2014: a pooled analysis of 1698 populationbased measurement studies with 19.2 million participants. Lancet. 2016;387(10026):137796.

2 Nuttall FQ. Body mass index: obesity, BMI, and health: a critical review. Nutr Today. 2015;50(3):117-28.

3 Rankinen T, Kim SY, Pérusse L, Després JP, Bouchard C. The prediction of abdominal visceral fat level from body composition and anthropometry: ROC analysis. Int J Obes Relat Metab Disord. 1999;23(8):801-9.

4 Bulik CM, Wade TD, Heath AC, Martin NG, Stunkard AJ, Eaves LJ. Relating body mass index to figural stimuli: population-based normative data for Caucasians. Int J Obes Relat Metab Disord. 2001;25(10):1517-24.

5 Wesnes K, Riise T, Casetta I, Drulovic J, Granieri E, Holmøy T, et al. Body size and the risk of multiple sclerosis in Norway and Italy: the EnvIMS study. Mult Scler. 2015;21(4):38895.

6 Lonnebotn M, Svanes C, Igland J, Franklin KA, Accordini S, Benediktsdottir B, et al. Body silhouettes as a tool to reflect obesity in the past. PloS One. 2018;13(4): e0195697.

7 Stunkard AJ, Sørensen T, Schulsinger F. Use of the Danish adoption register for the study of obesity and thinness. Res Publ Assoc Res Nerv Ment Dis. 1983;60:115-20.
8 Dratva J, Bertelsen R, Janson C, Johannessen A, Benediktsdóttir B, Bråbäck L, et al. Validation of self-reported figural drawing scales against anthropometric measurements in adults. Public Health Nutr. 2016;19(11): 1944-51.

9 Kaufer-Horwitz M, Martínez J, Goti-Rodríguez LM, Avila-Rosas H. Association between measured BMI and self-perceived body size in Mexican adults. Ann Hum Biol. 2006;33(56):536-45.

10 Bays HE, Bazata DD, Fox KM, Grandy S, Gavin JR 3rd. Perceived body image in men and women with type 2 diabetes mellitus: correlation of body mass index with the figure rating scale. Nutr J. 2009;8:57.

11 Conti MA, Ferreira ME, de Carvalho PH, Kotait MS, Paulino ES, Costa LS, et al. Stunkard figure rating scale for brazilian men. eating and weight disorders. Eat Weight Disord. 2013;18(3):317-22.

12 Ribeiro GA, Giampietro HB, Barbieri LB, Pacheco RG, Queiroz R, Ceneviva R. Body perception and bariatric surgery: the ideal and the possible. Arq Bras Cir Dig. 2013;26(2): 124-8.

13 Lynch E, Liu K, Wei GS, Spring B, Kiefe C, Greenland $\mathrm{P}$. The relation between body size perception and change in body mass index over 13 years: the coronary artery risk development in young adults (CARDIA) study. Am J Epidemiol. 2009;169(7):85766.
14 Carlsson LMS, Sjöholm K, Jacobson P, Andersson-Assarsson JC, Svensson PA, Taube $\mathrm{M}$, et al. Life expectancy after bariatric surgery in the Swedish obese subjects study. N Engl J Med. 2020;383(16): 1535-43.

15 Larsson I, Lindroos A, Lystig TC, Näslund I, Sjöström L. Three definitions of the metabolic syndrome: relations to mortality and atherosclerotic morbidity. Metab Syndr Relat Disord. 2005;3(2):102-12.

16 Youden WJ. Index for rating diagnostic tests. Cancer. 1950;3(1):32-5.

17 Slade PD. What is body image? Behav Res Ther. 1994;32(5):497-502.

18 Hosseini SA, Padhy RK. Body image distortion. StatPearls. Treasure Island (FL): StatPearls Publishing Copyright (C) 2020, StatPearls Publishing LLC; 2020.

19 Phillipou A, Castle DJ, Rossell SL. Anorexia nervosa: eating disorder or body image disorder? Aust N Z J Psychiatry. 2017: 4867417722640.

20 Docteur A, Urdapilleta I, Defrance C, Raison J. Body perception and satisfaction in obese, severely obese, and normal weight female patients. Obesity. 2010;18(7):1464-5.

21 Smeets MA, Smit F, Panhuysen GE, Ingleby JD. Body perception index: benefits, pitfalls, ideas. J Psychosom Res. 1998;44(3-4):45764.

22 Gadsby S. Distorted body representations in anorexia nervosa. Conscious Cogn. 2017;51: $17-33$. 
23 Ferris WF, Crowther NJ. Once fat was fat and that was that: our changing perspectives on adipose tissue. Cardiovasc J Afr. 2011;22(3): 147-54.

24 RickGardner MBNF, Jackson NA. Methodological concerns when using silhouettes to measure body image. Percept Mot Skills. 1998;86:387-95.

25 Ricciardi R, Talbot LA. Use of bioelectrical impedance analysis in the evaluation, treatment, and prevention of overweight and obesity. J Am Acad Nurse Pract. 2007;19(5):23541.

26 Hach S, Schütz-Bosbach S. Sinistrals' upper hand: evidence for handedness differences in the representation of body space. Brain Cogn. 2010;72(3):408-18.
27 Guardia D, Metral M, Pigeyre M, Bauwens I, Cottencin O, Luyat M. Body distortions after massive weight loss: lack of updating of the body schema hypothesis. Eating and weight disorders. Eat Weight Disord. 2013;18(3): 333-6.

28 Thompson JK. The adjustable light beam method for the assessment of size estimation accuracy: description, psychometrics and normative data. Int J Eat Disord. 1988;7:5216.
29 Sorbara M, Geliebter A. Body image disturbance in obese outpatients before and after weight loss in relation to race, gender, binge eating, and age of onset of obesity. Int J Eat Disord. 2002;31(4):416-23.

30 Merrill RM, Richardson JS. Validity of selfreported height, weight, and body mass index: findings from the National Health and Nutrition Examination Survey. Preventing chronic disease. 2001-20062009;6(4):A121.

31 Helsinki WMADo. Ethical Principles For Medical Research Involving Human Subjects. Helsinki, Finland, 1964, amended in Tokyo, Japan, 1975, Venice, Italy, 1983, Hong Kong, 1989. 